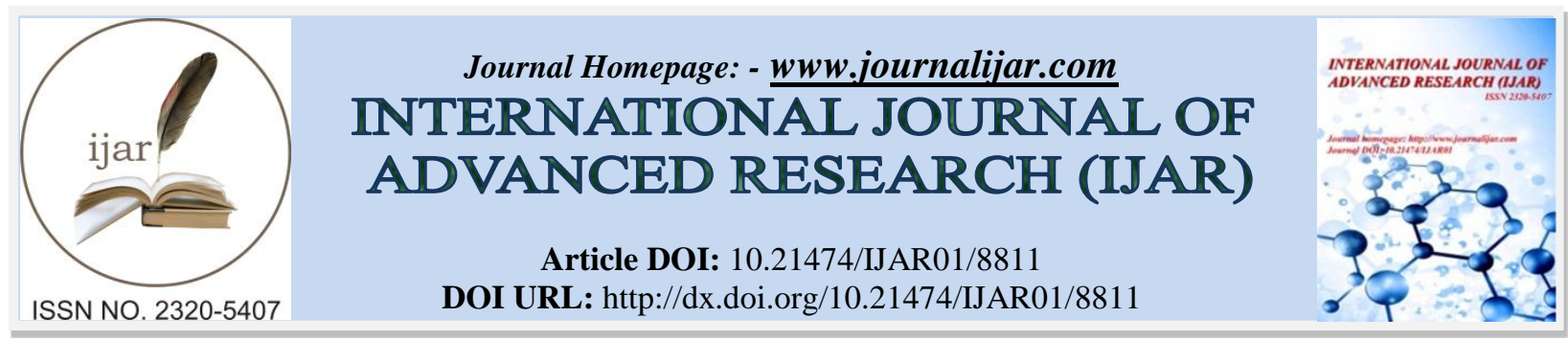

RESEARCH ARTICLE

\title{
EVOLUTION OF CONDUCTION MECHANISM IN THICK FILM RESISTORS
}

\author{
K. S. R. C. Murthy. \\ Accurex Solutions (P) Ltd., \# 782, $3^{\text {rd }}$ Main, $1^{\text {st }}$ Cross, BEML Layout, $5^{\text {th }}$ Stage, Rajarajeswari Nagar, Bangalore 560
} 098, India.

\section{Manuscript Info}

Manuscript History

Received: 05 February 2019

Final Accepted: 07 March 2019

Published: April 2019

Key words:-

thick film resistors, hybrids, conduction

mechanism, electrical properties,

microcircuits.

\section{Abstract}

When a printed and dried thick film resistor is subjected to firing, it undergoes many structural changes giving rise to various possibilities of electrical conduction. A study of these possibilities could be very interesting. An attempt was made in the present study to freeze these structures and to understand their influence on the electrical properties of the resistor.

\section{Introduction:-}

Thick Film Resistors in Hybrid Microcircuits are fabricated from thixotropic screen printable pastes. These pastes consist of a functional phase (e.g. Ruthenium Oxide or Bismuth Ruthenate), an inorganic binder (e.g. Lead borosilicate Glass), an organic binder (e.g. Ethyl Cellulose) and organic vehicle (e.g. Butylcarbitol Acetate) and various other organic thinners (Added to achieve desired viscosity and screen-printability). The pastes are screen printed onto a ceramic substrate usually $96 \%$ alumina.

The wet resistor film, after screen-printing, is initially dried in a dryer at $125^{\circ} \mathrm{C}$ where the volatile organic thinners get evaporated. Subsequently the dried film is fired in a conveyor-firing furnace over a temperature profile recommended by the paste maker. A typical profile is of 60 -minute duration with $850^{\circ} \mathrm{C}$ peak firing temperature and 10 minutes soak time. Commercial inks are available with sheet resistivity in decade values from $1 \mathrm{Ohm} / \square$ to $10^{7}$ $\mathrm{Ohm} / \square$. Such a wide variation in sheet resistivity is achieved by changing the volume fraction of functional phase in the fired resistor from about $60 \%$ to $5 \%$. These film resistors with interesting electrical properties such as low TCR (Temperature Coefficient of Resistance) values, a + ve to - ve switch-over in TCR at a specific temperature, low Hall mobility, low activation energies for conduction, low Seebeck coefficient, low magneto-resistance and absence of any significant high-field effects etc. have attracted lot of attention [1-20].

A number of theories have been put forward to explain the electrical properties of these resistors. However, all the conduction mechanisms hither to proposed are confined to fully processed resistors. Little attention has been paid to changes in the electrical behavior of the film as it travels through the firing profile. In fact, during firing, the resistor film undergoes a number of physicochemical changes as well as changes in its microstructure. A study on the effect of these changes on electrical properties of the film could be helpful in understanding and controlling the complex conduction behavior of these films. In the present study an attempt has been made to freeze the microstructure of the film from different stages of firing process and to study its electrical properties.

Corresponding Author:- K. S. R. C. Murthy. 


\section{Materials and Methods:-}

The test samples were drawn from prototyping line of thick film hybrids for 6 and $13 \mathrm{GHz}$ DMS (Digital Microwave System) equipment. The samples were drawn after drying of screen-printed resistors. Initially conductor terminations were screen printed on $96 \%$ Alumina substrates of Kyocera make and were dried and fired through $850^{\circ} \mathrm{C}$ with one-hour cycle time and 10 minutes soak time. Subsequently resistor films were screen-printed aligning suitably with the pre-fired conductor terminations. Each substrate consisted of not less than 75 resistors and resistors varied in their geometry with an aspect ratio from $1 / 3$ to $3 / 1$.

Assay of paste materials used in the present study is given below in Table-1. These materials were Shoei / DuPont make and composition as per the data sheets of supplier. The study was confined to resistor pastes with sheet resistivity of $1,100,1 \mathrm{~K}, 10 \mathrm{~K}, 100 \mathrm{~K}$ and $1 \mathrm{M}$ Ohm respectively. D-5670 $\mathrm{Ag} / \mathrm{Pd}$ paste was used for resistor terminations.

The wet films were dried in a BTU conveyor dryer at $125^{\circ} \mathrm{C}$. The films were then fired through MRL Firing Furnace at various temperatures from $500^{\circ} \mathrm{C}$ to $850^{\circ} \mathrm{C}$ and for different soak times from 1.5 to 23 minutes. Fired film thickness was within the process tolerance limits of $10+/-2$ microns.

Electrical resistance was measured with HP LCR Meter Model No. 6234 at difference frequencies - 100, 120, 1000, $10 \mathrm{~K}, 100 \mathrm{~K} \mathrm{~Hz}$ Frequencies respectively. Temperature variation of resistance was measured with the help of a digitally controlled hot plate between $20^{\circ} \mathrm{C}$ and $300^{\circ} \mathrm{C}$. Sample was stabilized for 20 minutes at each test temperature. Samples include those dried as well as fired at different firing temperatures and soak times.

\section{Results:-}

Resistance of dried samples was found to be quite high (More than $50 \mathrm{M} \mathrm{Ohm}$ ) for all

Table -1: Assay of paste materials used

\begin{tabular}{|l|l|l|c|c|}
\hline Paste Code & \multirow{2}{*}{$\begin{array}{l}\text { Jar Value } \\
\text { In Ohms/ square }\end{array}$} & & Functional Phase & \multicolumn{2}{|c|}{ Quoted TCR In ppm/ ${ }^{\mathbf{0}} \mathbf{C}$} \\
\cline { 4 - 5 } & 1.204 & $\mathrm{Pt}$ & 76 & $\mathbf{C o t d}$ \\
\hline SHOEI R9010 & 91.000 & $\mathrm{RuO}_{2}$ & 7 & 49 \\
\hline SHOEI R9210 & $\mathrm{Bi}_{2} \mathrm{Ru}_{2} \mathrm{O}_{7}$ & 45 & -17 \\
\hline DUPONT 1729 & $0.966 \mathrm{~K}$ & $\mathrm{Bi}_{2} \mathrm{Ru}_{2} \mathrm{O}_{7}$ & 45 & -16 \\
\hline DUPONT 1739 & $9.780 \mathrm{~K}$ & $\mathrm{RuO}_{2}$ & -35 & -51 \\
\hline SHOEI R9510 & $102.200 \mathrm{~K}$ & $\mathrm{RuO}_{2}$ & -22 & -43 \\
\hline SHOEI R9610 & $1.013 \mathrm{M}$ & \multicolumn{2}{c}{} \\
\hline
\end{tabular}

the resistors studied, except for R9010 (1-Ohm Paste) resistors. Resistors printed from 1K Paste and 10K Paste were found to have high resistance values when fired at temperatures below $650^{\circ} \mathrm{C}$ and $675^{\circ} \mathrm{C}$ (Soak time: 1.5 minutes) respectively while $100 \mathrm{~K}$ paste resistors showed high resistance $(>50 \mathrm{M} \mathrm{Ohm})$ for all firing temperatures between $500^{\circ} \mathrm{C}$ and $850^{\circ} \mathrm{C}$ except for $700^{\circ} \mathrm{C}$ for the same soak time. $1 \mathrm{M}-\mathrm{Ohm}$ resistor exhibited high resistance for all these firing temperatures for a soak time of 1.5 minutes. However, when the soak time at $850^{\circ} \mathrm{C}$ is increased to 10 minutes, the resistance decreased significantly.

Fig.1 highlights the influence of peak firing temperature on normalized resistance of 100-Ohm, 1K-Ohm and 10KOhm paste resistors respectively for 1.5 minutes soak time.

Fig. 2 shows the effect of soak time on normalized resistance for above resistors for a peak firing temperature of $850^{\circ}$ C. Fig. 3 shows variation in room temperature resistance of $100,1 \mathrm{~K}$ and $10 \mathrm{~K}$ paste resistors with degree of sintering. Degree of sintering is indicated approximately basing on firing temperatures and soak times.

The resistance plotted in Fig.1 and Fig. 2 is normalized to the respective design value. A variation of $+/-20 \%$ from the design value, in fired values of resistance in a batch process is quite common in Thick Film Hybrid technology.

However, this can be kept fairly at minimum to $+/-5 \%$ by considering resistors fabricated on the same substrate in the same print stroke where almost all the screen printing parameters are held identical for them and also by 
selecting only those resistors which vary in their dried film thickness within $+/-4$ microns among themselves. In all the other plots where temperature dependence of resistance has been shown, the resistance is normalized to the respective room temperature value.

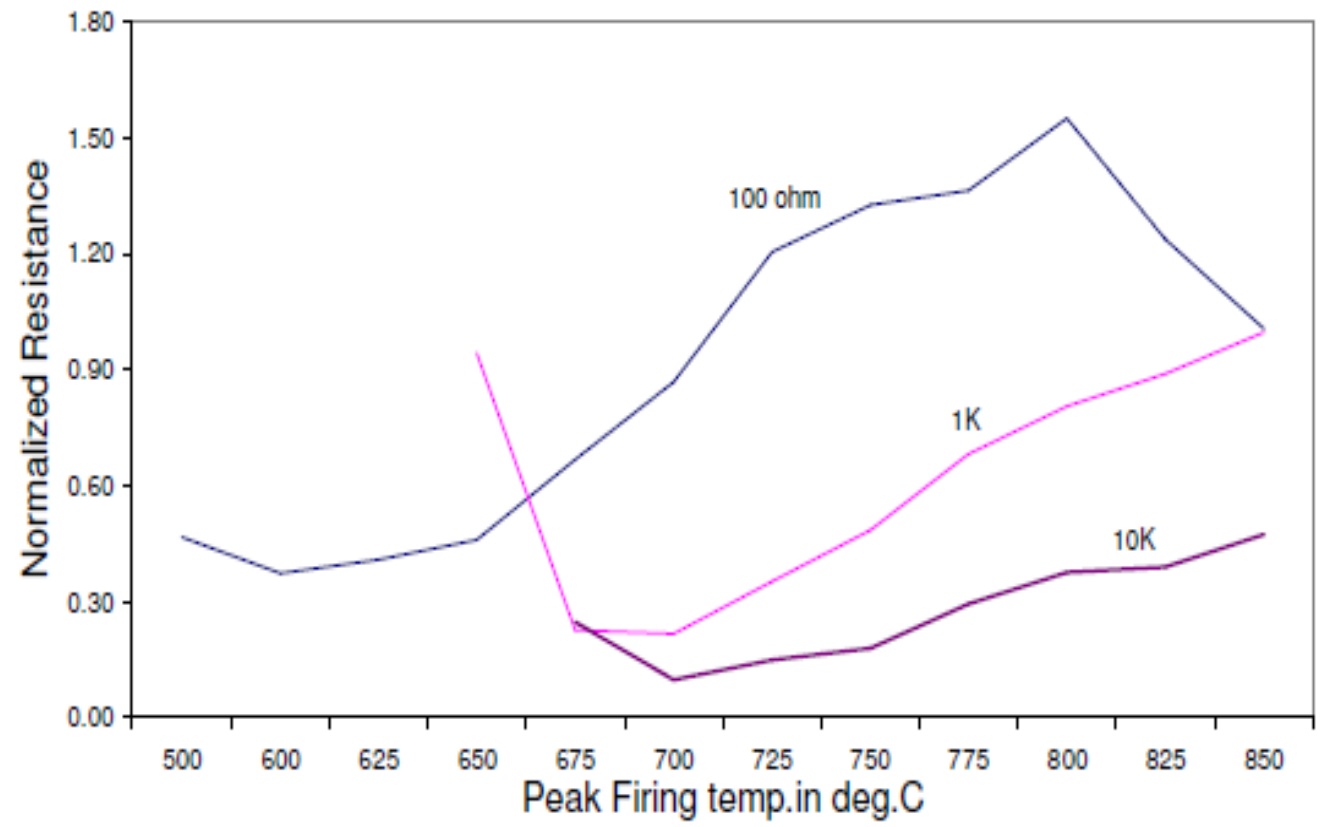

Fig.1 Variation in RT Resistance with firing temperature for 100, $1 \mathrm{~K}$ and $10 \mathrm{~K}$ ohm paste resistors (soak time 1.5 minutes)

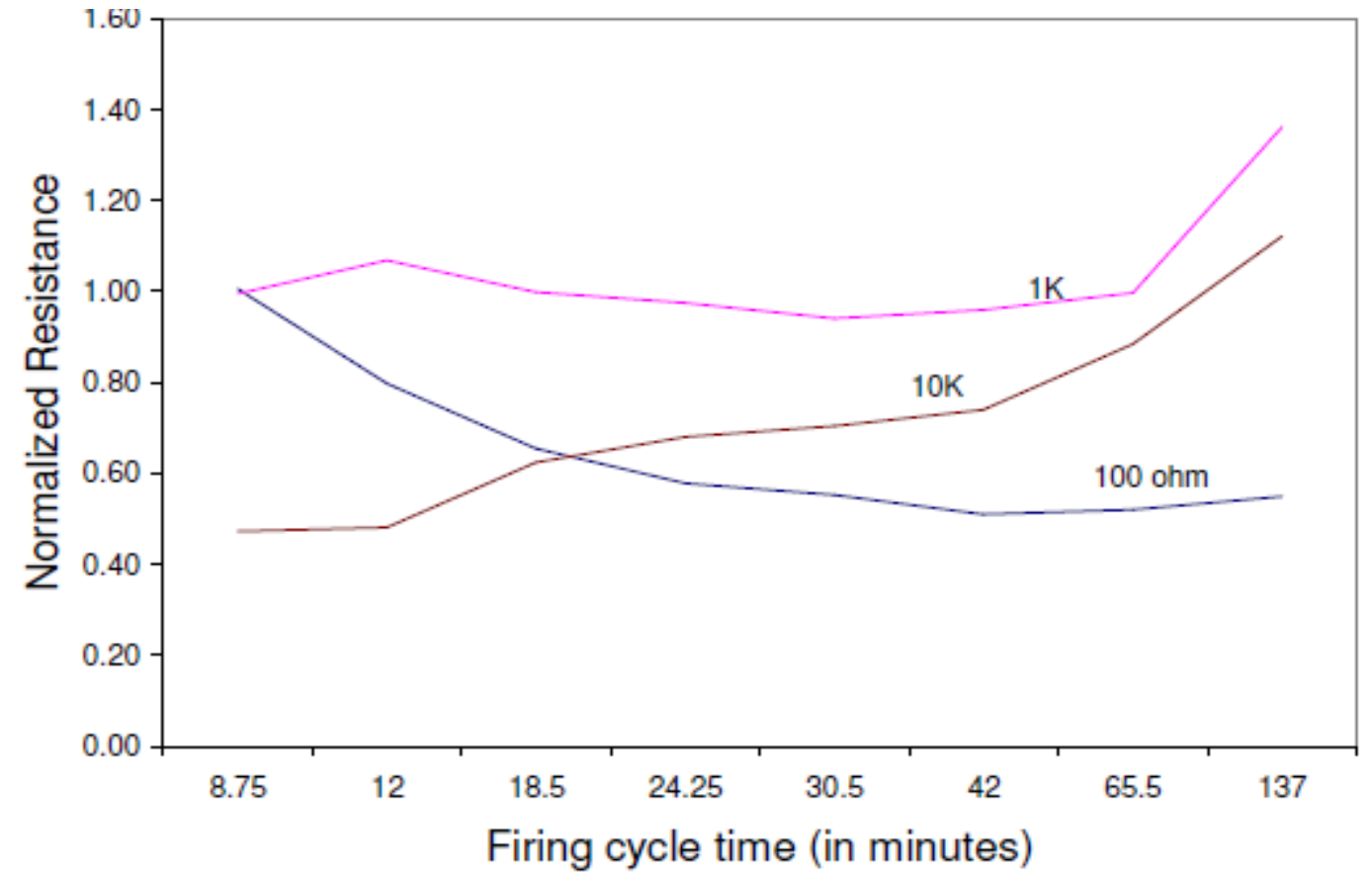

Fig.2 Variation in RT Resistance with firing cycle time for 100, $1 \mathrm{~K}$ and $10 \mathrm{Kohm}$ paste resistors (peak firing temp $850^{\circ} \mathbf{C}$ )

Thermal cycling effects on resistance drift for $1-\mathrm{ohm}$ and $100 \mathrm{ohm}$ resistors paste resistors, fired at $500^{\circ} \mathrm{C}$ are shown in Fig.4 and Fig.5 respectively. 


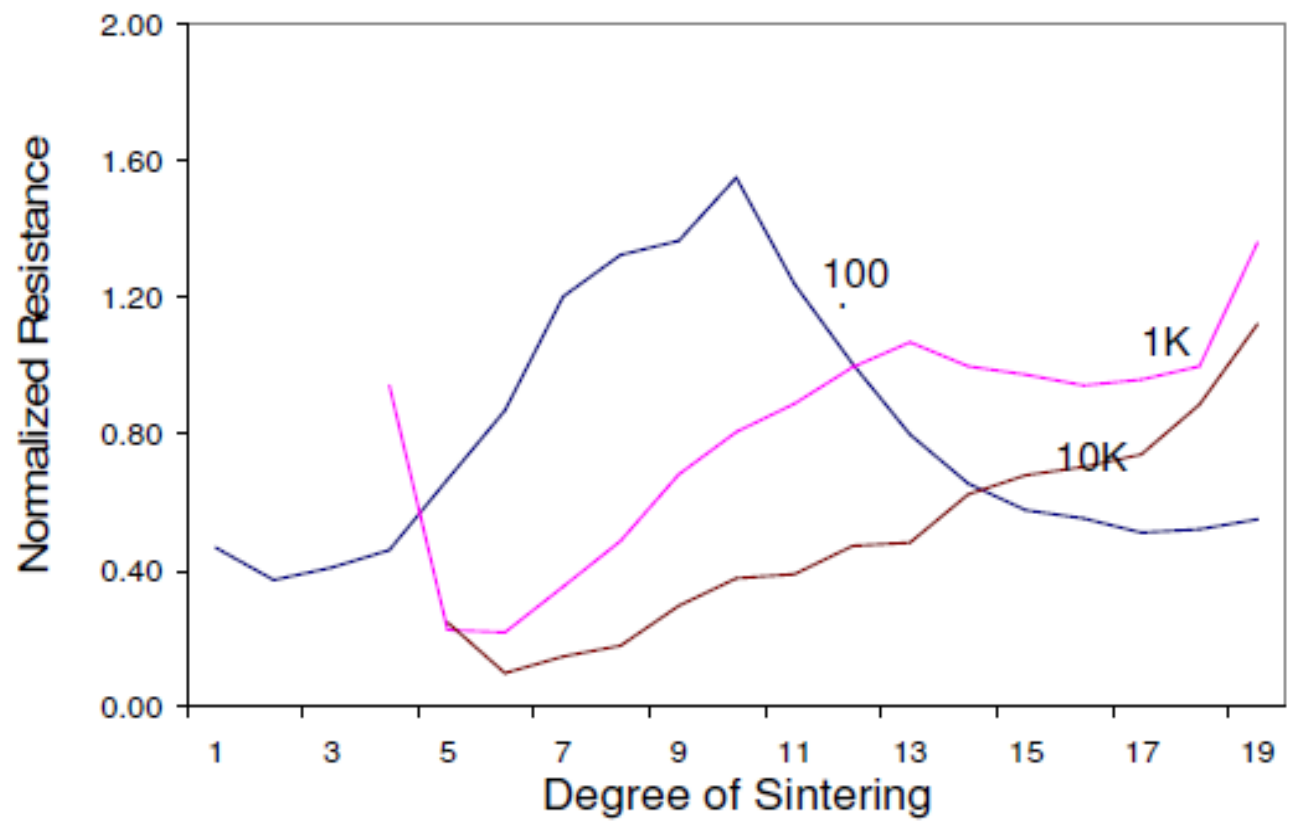

Fig. 3 Variation in Resistance with degree of sintering for 100, $1 \mathrm{~K}$ and $10 \mathrm{~K}$ ohm paste resistors

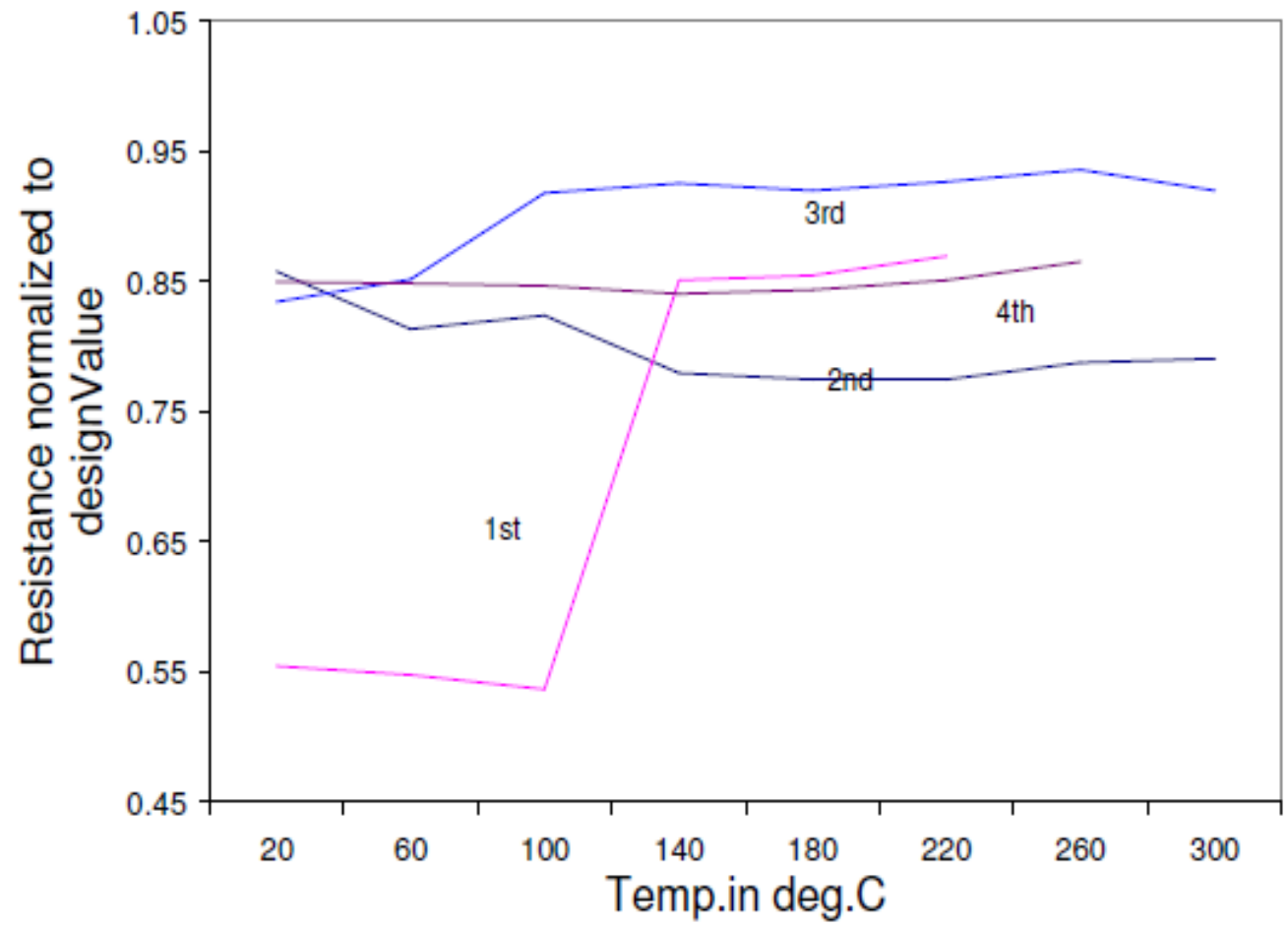

Fig.4 Thermal cycling effect on temperature variation of resistance on 1-ohm paste resistors for $500^{\circ} \mathrm{C}$ fired samples (soak time 1.5 minutes) 


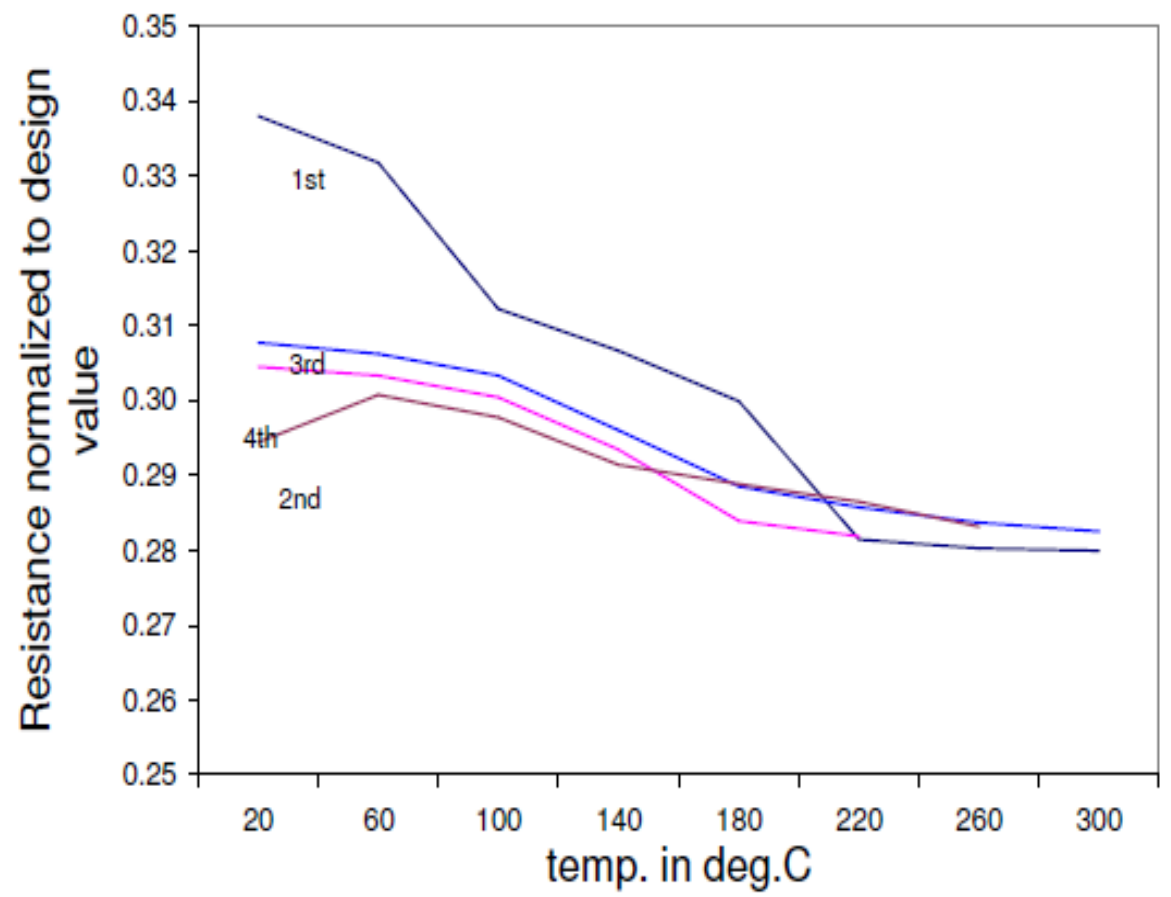

Fig.5 Thermal cycling effect on temperature variation of resistance on $100 \mathrm{ohm}$ paste resistors for $500^{\circ} \mathrm{C}$ fired samples (soak time 1.5 minutes)

Fig.6 gives temperature dependence of resistance for the films of $1 \mathrm{ohm}$ paste resistors fired at 600,700 and $850^{\circ} \mathrm{C}$ respectively. In all these plots normalized resistance, normalized to its room temperature value, has been plotted against temperature.

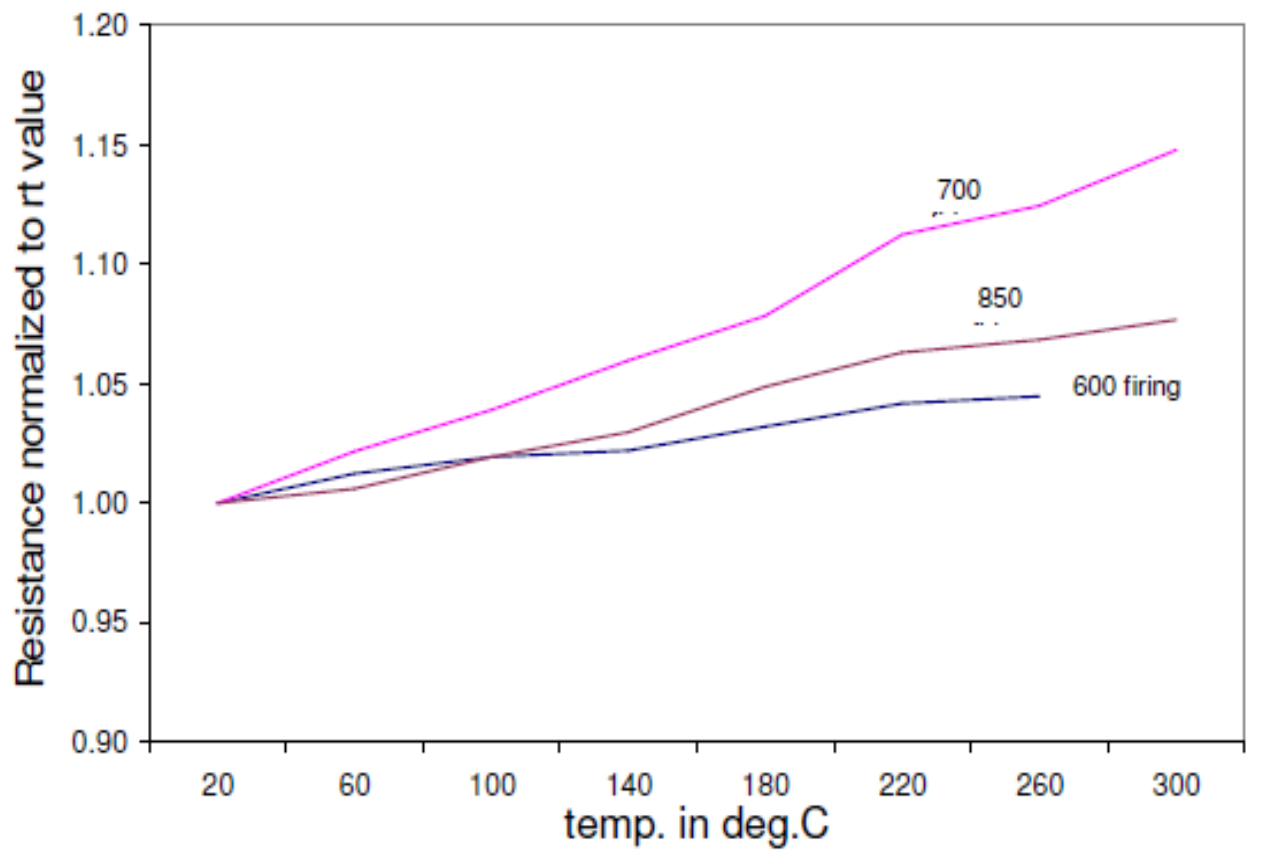

Fig.6 Resistance variation with temperature for $1 \mathrm{ohm}$ paste resistors fired at 600 , 700 and $850^{\circ} \mathrm{C}$ (soak time 1.5 minutes) 
Fig.7 gives temperature dependence of resistance for the films of $100 \mathrm{ohm}$ paste resistors fired at various temperatures between $600^{\circ} \mathrm{C}$ and $850^{\circ} \mathrm{C}$ respectively.

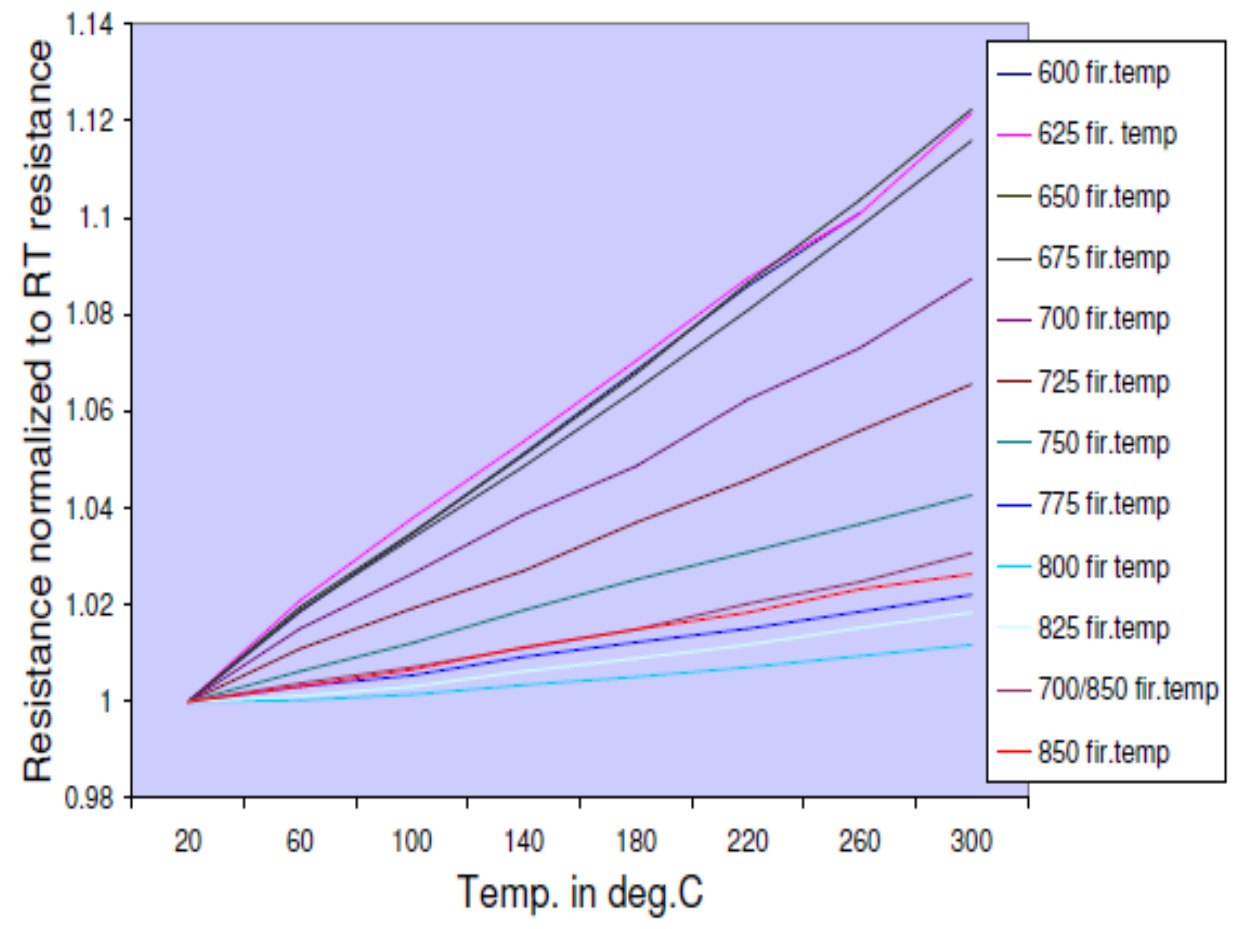

Fig.7 Resistance variation with temperature for $100 \mathrm{ohm}$ paste resistors fired at different temperatures (soak time 1.5 minutes)

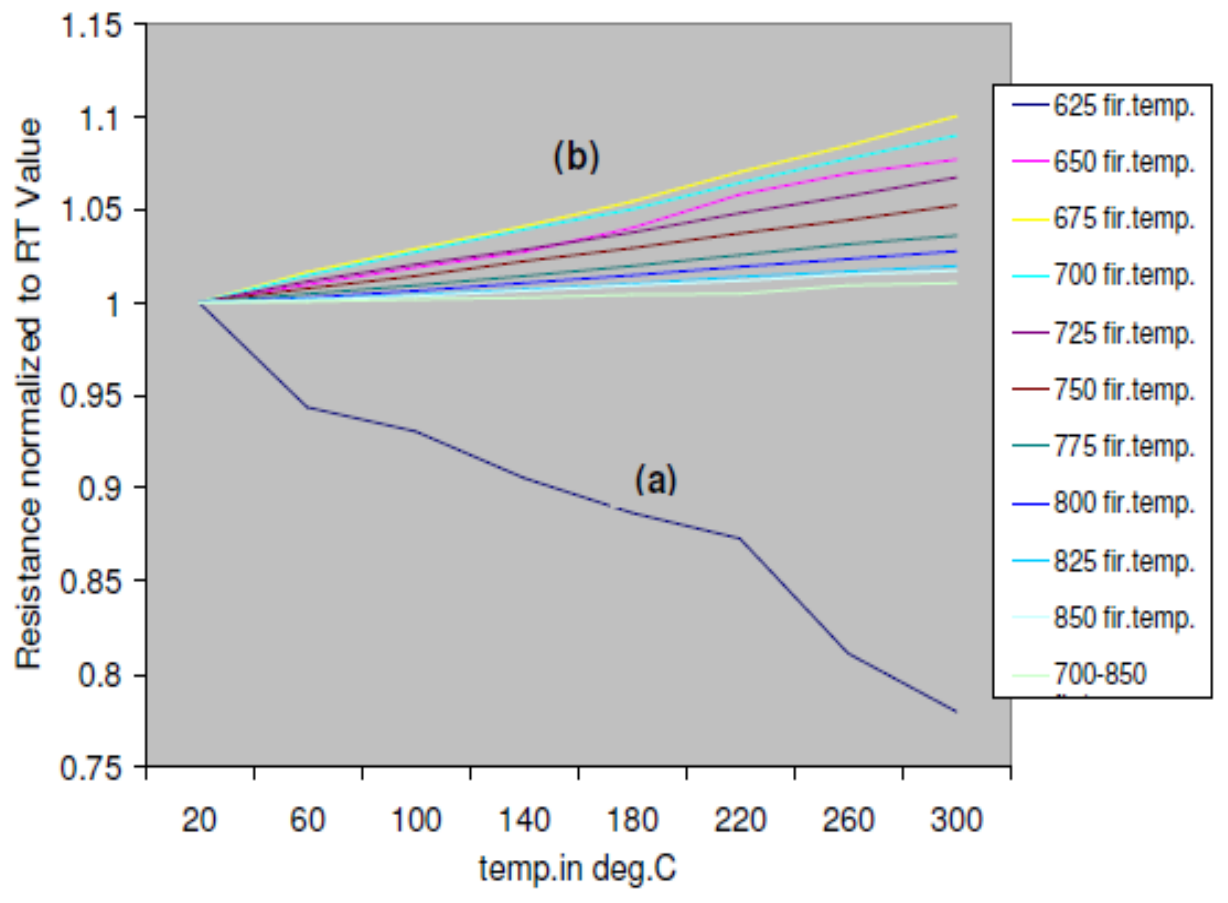

Fig.8 Resistance variation with temperature for $1 \mathrm{~K}$ ohm paste resistors fired at different temperatures (soak time 1.5 minutes) 
Thus Fig. 8 and Fig.9 show the temperature variation of resistance between $20^{\circ} \mathrm{C}$ and $300^{\circ} \mathrm{C}$ for resistor films printed from $1 \mathrm{~K}$ and $10 \mathrm{~K}$ pastes respectively and fired at various temperatures between $650^{\circ} \mathrm{C}$ and $850^{\circ} \mathrm{C}$.

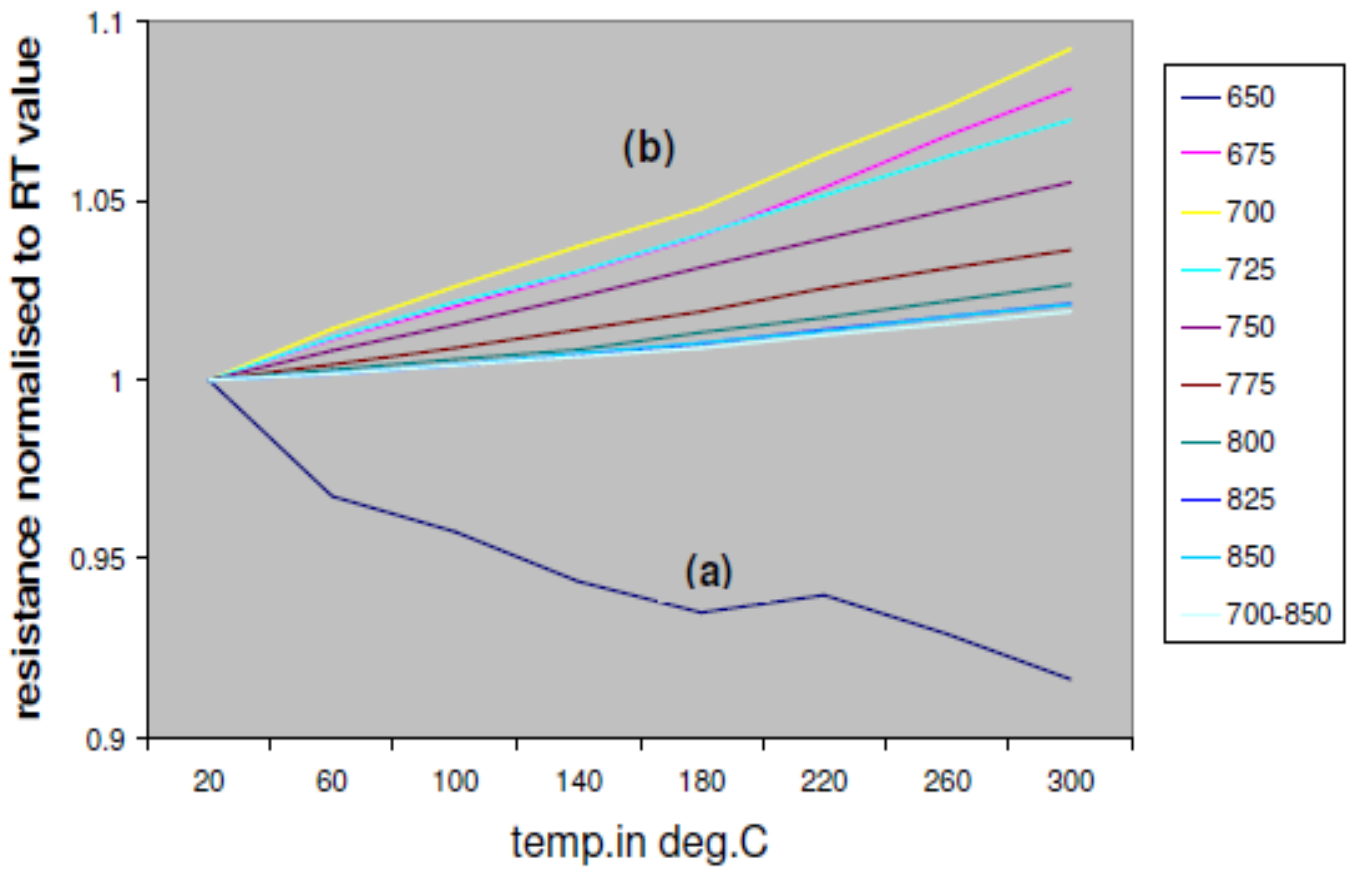

Fig.9 Resistance variation with temperature for $10 \mathrm{~K}$ ohm paste resistors fired at different temperatures (soak time 1.5 minutes)

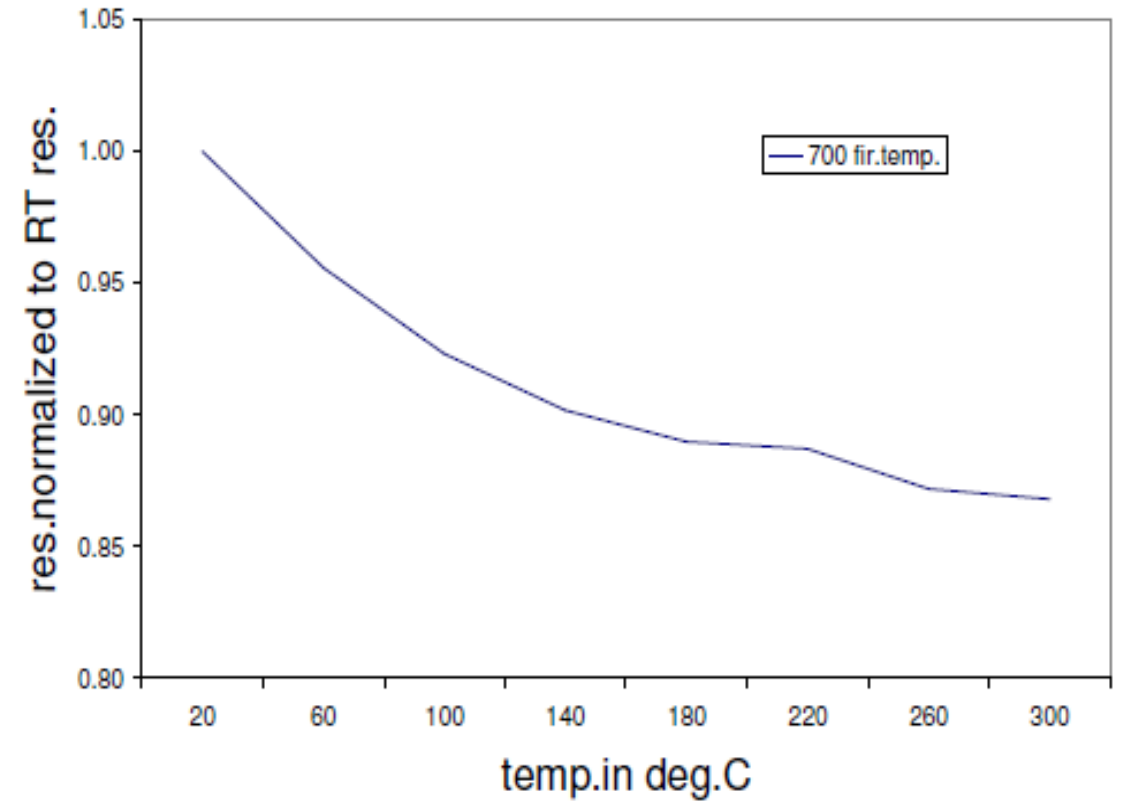

Fig.10 Resistance variation with temperature for $100 \mathrm{~K} \mathrm{ohm}$ paste resistors fired at $700^{\circ} \mathrm{C}$ (soak time 1.5 minutes) 
Temperature variation of resistance between $20^{\circ} \mathrm{C}$ and $300^{\circ} \mathrm{C}$ for this $100 \mathrm{~K}$ paste resistor fired at $700^{\circ} \mathrm{C}$ is plotted in Fig.10. All the figures from Fig.4 to Fig.10 refer to a soaking time of 1.5 minutes at respective peak firing temperatures.

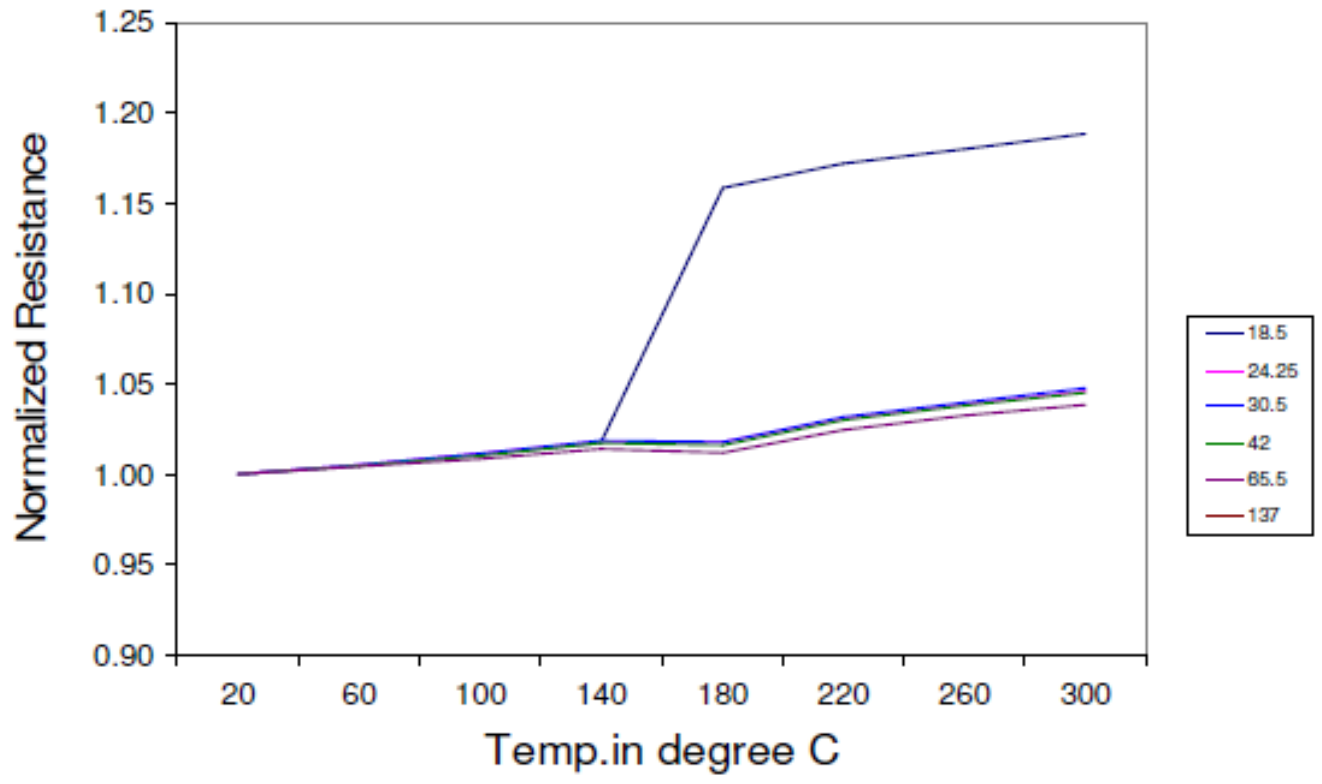

Fig.11 Resistance variation with temperature for $100 \mathrm{ohm}$ paste resistors fired at $850^{\circ} \mathrm{C}$ for different cycle times (or soak times)

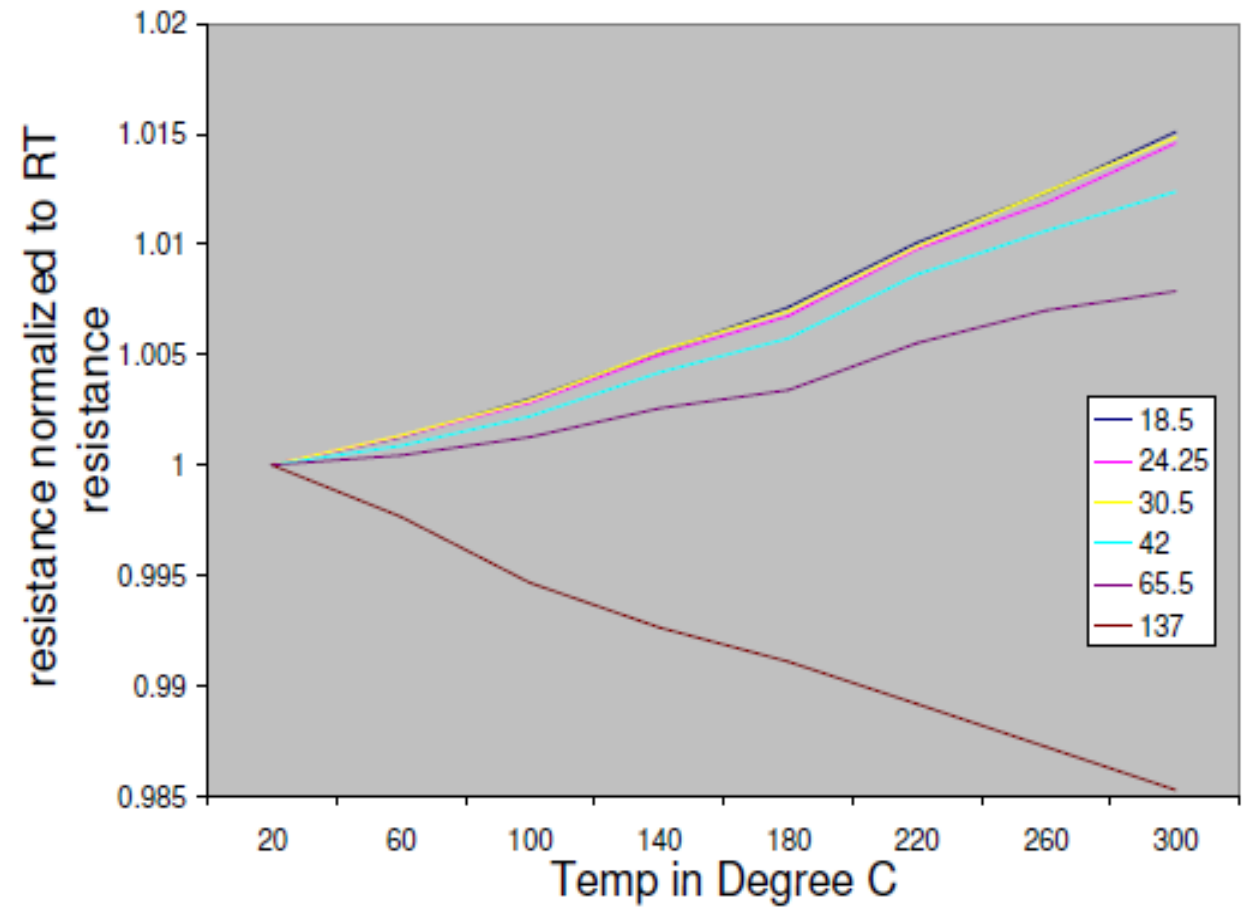

Fig.12 Resistance variation with temperature for $1 \mathrm{~K}$-ohm paste resistors fired at $850^{\circ} \mathrm{C}$ for different firing cycle times (Soak times) 
The influence of soak time at a peak firing temperature of $850^{\circ} \mathrm{C}$, on temperature variation of resistance between $20^{\circ} \mathrm{C}$ and $300^{\circ} \mathrm{C}$ for $100,1 \mathrm{~K}, 10 \mathrm{~K}, 100 \mathrm{~K}$ and $1 \mathrm{M}$ paste resistors is shown in Fig. 11 to Fig. 15 respectively.

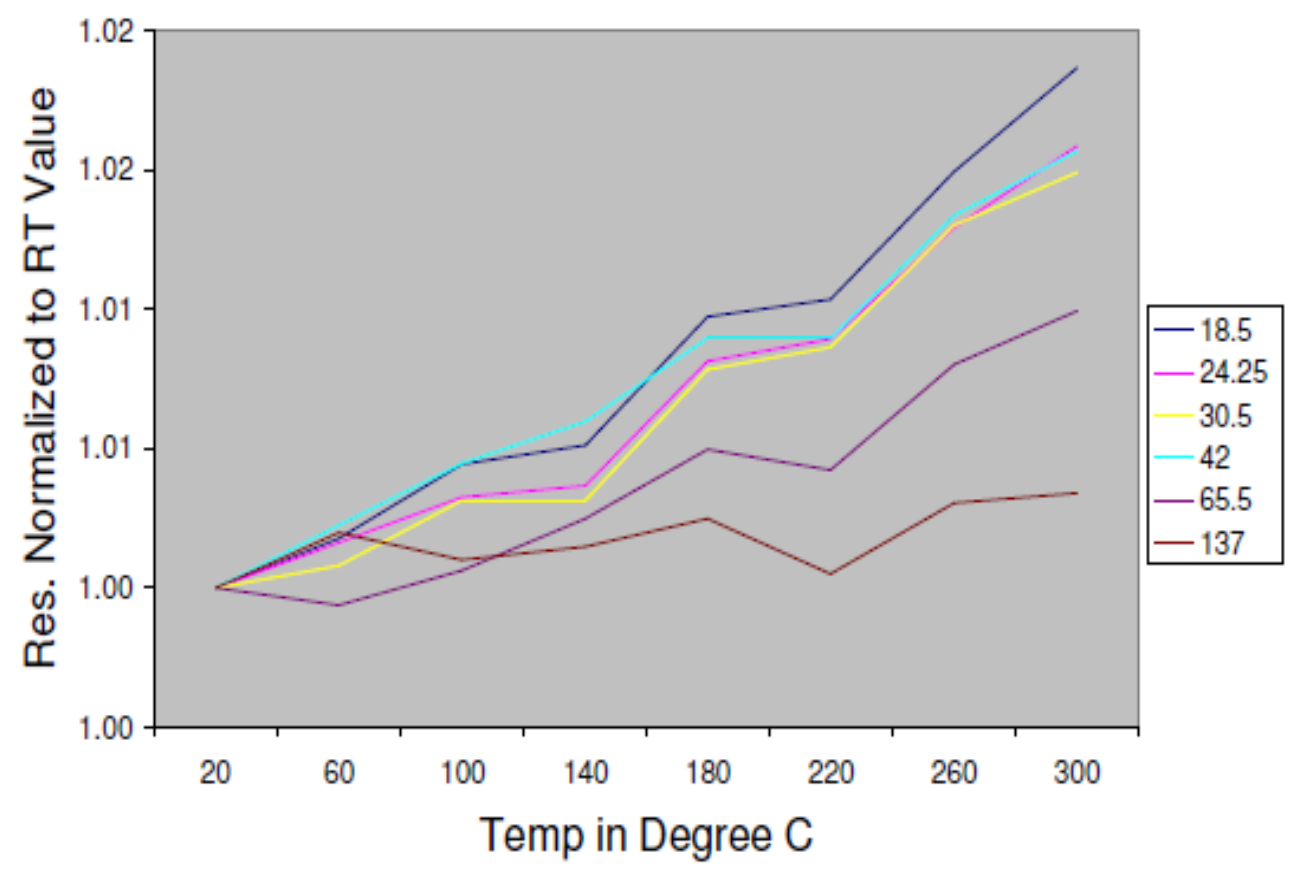

Fig.13 Resistance variation with temperature for $10 \mathrm{~K} \mathrm{ohm} \mathrm{paste} \mathrm{resistors} \mathrm{fired} \mathrm{at} 850^{\circ} \mathrm{C}$ for different firing cycle times

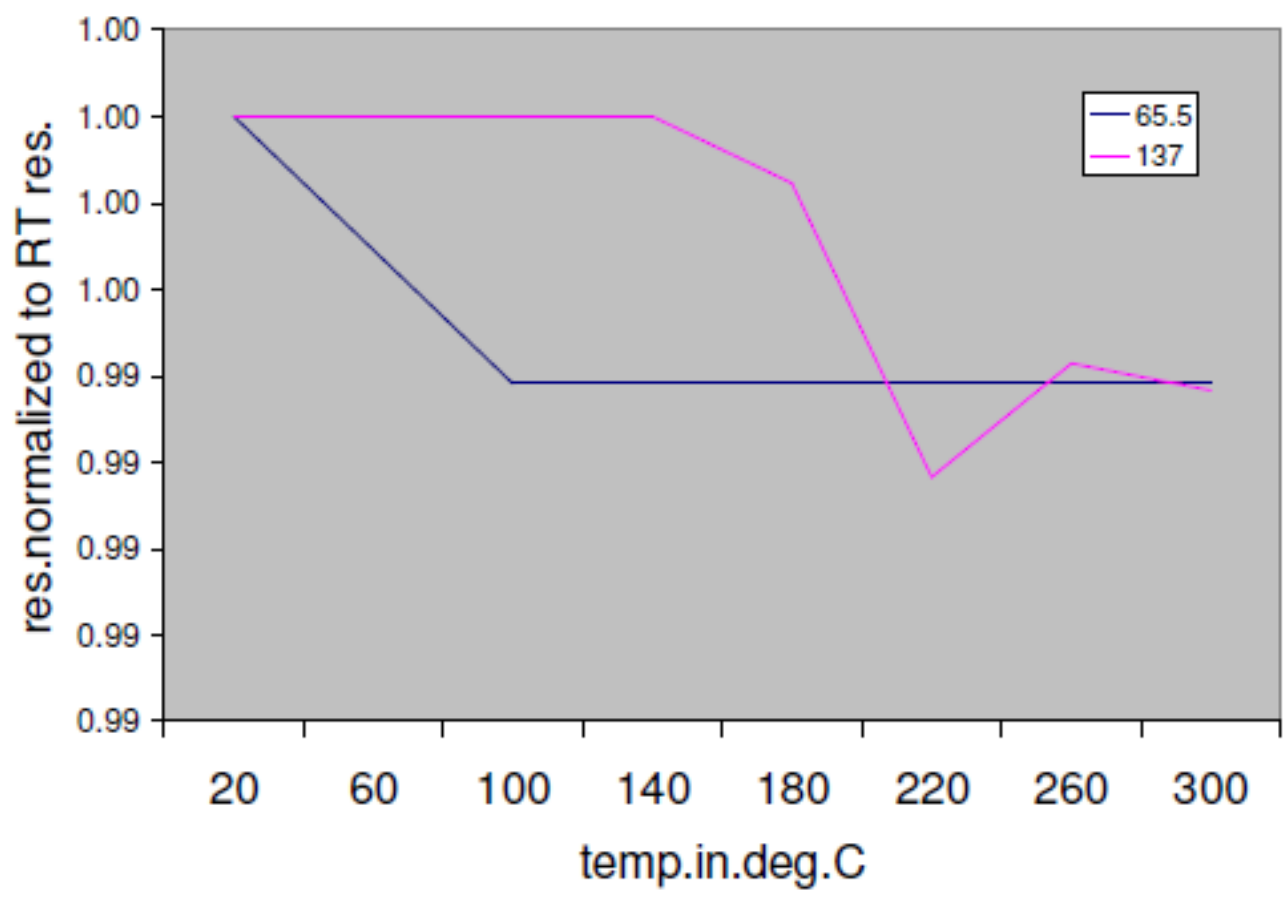

Fig.14 Resistance variation with temperature for $100 \mathrm{~K}$ ohm paste resistors fired at $850^{\circ} \mathrm{C}$ for different firing cycle times (or soak times) 


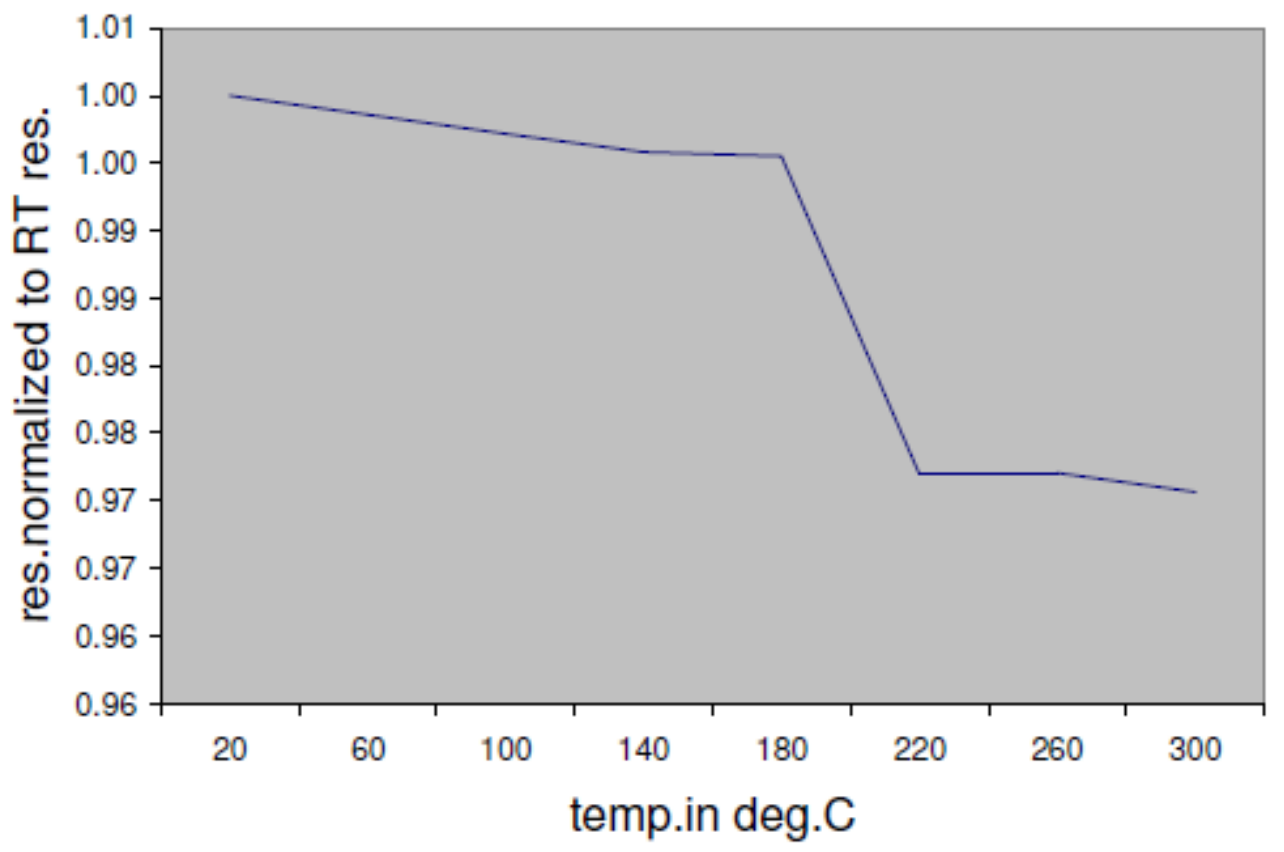

Fig.15 Resistance variation with temperature for $100 \mathrm{~K}$ ohm paste resistors fired at $850^{\circ} \mathrm{C}$ for 137 minutes firing cycle time

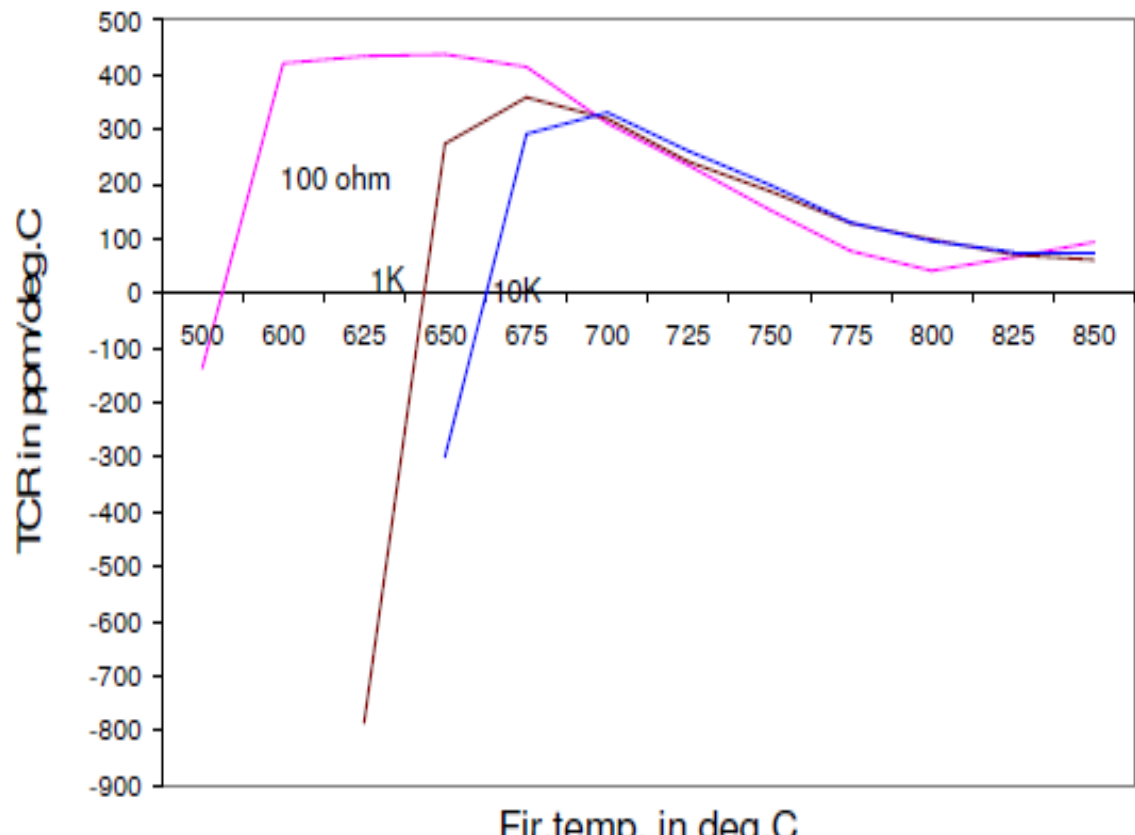

Fig.16 Effect of Firing Temperature on TCR for 100, 1K and $10 \mathrm{~K}$ paste resistors (Soak time 1.5 minutes)

Fig.16 shows the effect of peak firing temperature (Soak time: 1.5 minutes) on Hot TCR for 100, $1 \mathrm{~K}$ and 10K paste resistors respectively, while the corresponding plot for various soak times (Peak firing temperature: $850^{\circ} \mathrm{C}$ ) is shown in Fig.17. 


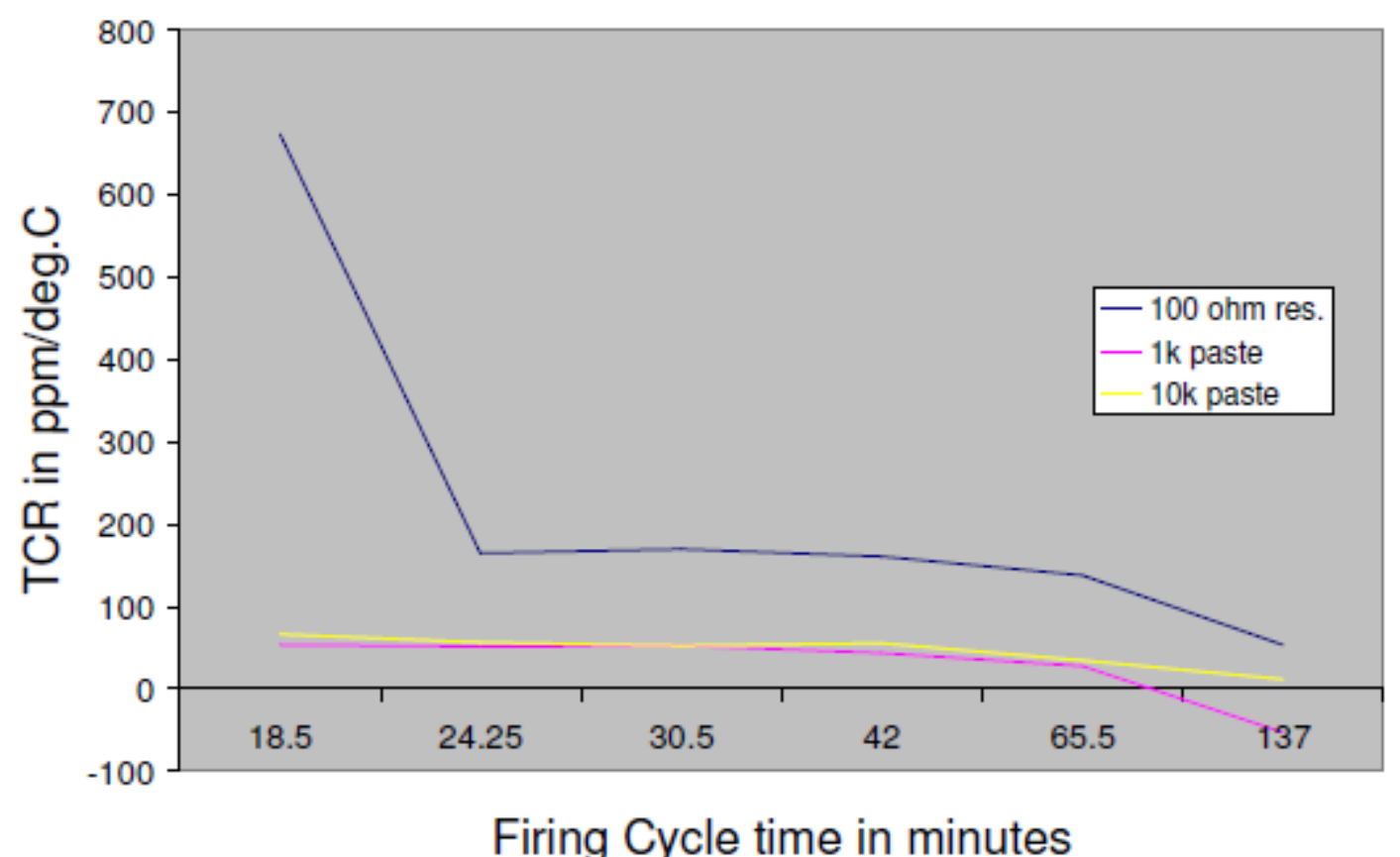

Fig.17 Effect of Firing Cycle time on TCR for 100, 1K and 10K paste resistors (Peak firing temperature $850^{\circ} \mathrm{C}$ )

\section{Discussion:-}

\section{IV.1. Dried Film Resistance:}

Initially when the printed wet film is dried, the conducting phase (Functional phase) becomes distributed in the polymer matrix, which is the organic binder. Depending on the volume fraction of this phase it is likely that the conduction particles are in physical contact for high volume fraction paste films. Such films may exhibit low resistance even just with drying without any necessity of high temperature firing. This is evident from the observed low resistance of dried films printed from 1-ohm paste in which volume fraction of conducting phase is expected to be more $\tan 65 \%$.

However, if such a physical contact does not exist, the resistance can be quite high due to insulating nature of organic binder, which separates the conducting particles. Thus the observed high resistance in case of dried film resistors processed with $100,1 \mathrm{k}, 10 \mathrm{k}, 100 \mathrm{k}$ and $1 \mathrm{M}$ ohm pastes can be attributed to isolated conducting particles/grains without any contact due to high insulating barriers provided by organic binder. Studies on microstructure of films of this type indicated that the size of the glass particles (Inorganic/ Permanent binder) is comparable with that of conducting particles initially. Hence it is unlikely that these glass particles inhibit the physical contact among conducting spheres in dried film.

Table - II gives room temperature resistance of resistors fired at different tempe-

ratures for a soak time of 1.5 minutes and TCR value of same is indicated in paranthesis. Table - III gives room temperature resistance of resistors fired at $850^{\circ} \mathrm{C}$ for different soak times. 
Table - II: Effect of Firing temperature on resistance of a typical thick film resistor for a soak time of 1.5 minutes

\begin{tabular}{|c|c|c|c|c|c|}
\hline \multirow{3}{*}{$\begin{array}{l}\text { Firing } \\
\text { Temp. } \\
\text { In }^{\circ} \mathrm{C} \\
\end{array}$} & \multicolumn{5}{|c|}{ Paste jar value in Ohms/square } \\
\hline & 1 & 100 & $1 \mathrm{~K}$ & $10 \mathrm{~K}$ & $100 \mathrm{~K}$ \\
\hline & \multicolumn{5}{|c|}{ Design Values [Resistance in Ohms] } \\
\hline & 1.400 & 130.00 & 470.00 & $18.10 \mathrm{~K}$ & $60.0 \mathrm{~K}$ \\
\hline 500 & $\begin{array}{l}1.673 \\
{[-44]}\end{array}$ & $\begin{array}{l}35.083 \\
{[-136]}\end{array}$ & - & - & - \\
\hline 600 & $\begin{array}{l}8.555 \\
{[166]}\end{array}$ & $\begin{array}{c}28.012 \\
{[421]}\end{array}$ & & & \\
\hline 625 & & $\begin{array}{c}30.697 \\
{[434]}\end{array}$ & $\begin{array}{l}1590.0 \\
{[-786]}\end{array}$ & & \\
\hline 650 & & $\begin{array}{c}34.486 \\
{[437]}\end{array}$ & $\begin{array}{c}442.77 \\
{[275]}\end{array}$ & $\begin{array}{c}802 \mathrm{~K} \\
{[-298]}\end{array}$ & \\
\hline 675 & & $\begin{array}{c}50.040 \\
{[414]}\end{array}$ & $\begin{array}{c}06.31 \\
{[359]}\end{array}$ & $\begin{array}{c}4.471 \mathrm{~K} \\
{[291]}\end{array}$ & \\
\hline 700 & $\begin{array}{l}1.911 \\
{[726]}\end{array}$ & $\begin{array}{c}65.220 \\
{[312]}\end{array}$ & $\begin{array}{c}102.62 \\
{[320]}\end{array}$ & $\begin{array}{c}1.798 \mathrm{~K} \\
{[330]}\end{array}$ & $\begin{array}{l}62.5 \mathrm{~K} \\
{[-472]}\end{array}$ \\
\hline 725 & & $\begin{array}{c}90.220 \\
{[234]}\end{array}$ & $\begin{array}{c}165.14 \\
{[241]}\end{array}$ & $\begin{array}{c}2.698 \mathrm{~K} \\
{[259]}\end{array}$ & \\
\hline 750 & & $\begin{array}{c}99.290 \\
{[152]}\end{array}$ & $\begin{array}{c}228.63 \\
{[187]}\end{array}$ & $\begin{array}{c}3.275 \mathrm{~K} \\
{[198]}\end{array}$ & \\
\hline 775 & & $\begin{array}{c}102.26 \\
{[78]}\end{array}$ & $\begin{array}{c}320.81 \\
{[129]}\end{array}$ & $\begin{array}{c}5.352 \mathrm{~K} \\
{[130]}\end{array}$ & \\
\hline 800 & & $\begin{array}{c}116.18 \\
42]\end{array}$ & $\begin{array}{c}378.3 \\
{[99]}\end{array}$ & $\begin{array}{c}6.821 \mathrm{~K} \\
{[95]}\end{array}$ & \\
\hline 825 & & $\begin{array}{c}92.807 \\
{[66]}\end{array}$ & $\begin{array}{c}417.63 \\
{[71]}\end{array}$ & $\begin{array}{c}7.066 \mathrm{~K} \\
{[76]}\end{array}$ & \\
\hline 850 & $\begin{array}{l}1.560 \\
484]\end{array}$ & $\begin{array}{c}75.384 \\
{[94]}\end{array}$ & $\begin{array}{c}467.82 \\
{[61]}\end{array}$ & $\begin{array}{c}8.557 \mathrm{~K} \\
{[75]}\end{array}$ & \\
\hline $700-850$ & & $\begin{array}{c}59.560 \\
{[109]}\end{array}$ & $\begin{array}{c}501.77 \\
{[38]}\end{array}$ & $\begin{array}{c}8.724 \mathrm{~K} \\
{[68]}\end{array}$ & \\
\hline
\end{tabular}

An attempt to find the TCR of the dried films of 1-ohm paste resistors could not be successful since the variation of resistance was erratic and irreproducible. This may be due to continuous rearrangements in particle-particle contacts, which are only physical in nature, due to expansion and contraction of organic binder while heating and cooling respectively.

\section{IV.2. Fired Films:}

When the dried films are subjected to a firing profile, in the burn out stage at about $500^{\circ} \mathrm{C}$ the organic vehicle gets totally burnt out. At this stage, again depending on the volume fraction of conducting phase, it is possible that the conducting particles / grains left behind may develop contacts leading to a substantial decrease in resistance. Sudden disappearance of insulating barrier and onset of contacts between conducting grains is likely to give rise to a steep decrease in resistance as observed in case of films printed from $100,1 \mathrm{k}$ and $10 \mathrm{k}$ pastes and fired at $500^{\circ} \mathrm{C}, 650^{\circ} \mathrm{C}$ and $675^{\circ} \mathrm{C}$ respectively.

Ascending order of firing temperatures for onset of contacts for these resistor films with increasing jar value of paste is in accordance with the decrease in volume fraction of the conducting phase. The probability and density of contacts is directly related to amount of conducting phase available in fired film. Thus in case of films processed from $1 \mathrm{k}$ and $10 \mathrm{k}$ pastes, insulating barriers still exist despite the burn out of organic binder for the firing temperatures below $650^{\circ} \mathrm{C}$ and $675^{\circ} \mathrm{C}$ respectively. Room temperature resistance of these films is quite high and decreases exponentially with temperature as shown in Fig $8 \& 9$ respectively. The barriers even after organic binder burnout in these films may arise due to relative increase in content of glass particles (Inorganic binder) with respect to conducting grains. 
As the firing temperature increases above $500^{\circ} \mathrm{C}$, the glass phase starts flowing. This may lead to movement of conducting particles, which in turn may lead to onset of contacts among themselves causing a substantial decrease in their room temperature resistance.

At still higher firing temperatures glass getting softened, gets sintered and its particle size grows. At these temperatures conducting particles being relatively small, adhere to bigger glass particles. They begin to rearrange in micro and macro networks increasing / decreasing resistance. Similarly prolonged firing at higher temperatures $\left(850^{\circ} \mathrm{C}\right)$ leads to doping of glass by conducting oxide.

To understand the nature of contacts developed and the nature of inter granular material between conducting grains and to know how the changes in microstructure during a firing cycle affects the electrical resistance of fired films, it is necessary to look into origin of conduction in thick film resistors. Also in view of a variety of microstructures possible within the film resistor depending on its process history, a brief review of various conduction models put forward hitherto could be quite helpful in interpreting the observed conduction behavior.

\section{IV.3. Origin of Conduction in Thick Film Resistors - A Brief Review:}

IV.3.1. Intrinsic Conduction due to Functional phase alone:

Conduction solely due to intrinsic conduction arising from functional phase has been ruled out owing to following factors:

$>$ Weak temperature dependence of resistance

$>$ Weak voltage dependence of Resistance

$>$ Low magnitude of Seebeck Coefficient, Hall mobility and magneto-resistance

The intrinsic room temperature resistivity and TCRs of conducting phases that may appear during firing of a thick film resistor are shown in Table-IV. The large differences in electrical properties between fired resistors and functional phase as shown in Tables II, III and IV support this assumption. Thus film resistivity with 4 to 5 orders of magnitude higher than the intrinsic resistivity of metal oxide (Functional Phase) grains indicates clearly that conduction mechanisms in film resistors are totally different from those in pure functional phase.

\section{Table - III: Effect of soak time on resistance of resistors fired at $850^{\circ} \mathrm{C}$}

\begin{tabular}{|c|c|c|c|c|c|}
\hline \multirow{2}{*}{$\begin{array}{c}\text { Soak } \\
\text { Time } \\
\text { minutes }\end{array}$} & \multicolumn{5}{|c|}{ Paste jar value in Ohms/square } \\
\cline { 2 - 6 } & $\mathbf{1 0 0}$ & \multicolumn{5}{|c|}{ 1K } & $\mathbf{1 0 K}$ & $\mathbf{1 0 0 K}$ & 1M \\
\hline & \multicolumn{5}{|c|}{ Design Value [Resistance in ohms] } \\
\hline & $\mathbf{1 3 0 . 0 0}$ & $\mathbf{4 7 0 . 0 0}$ & $\mathbf{1 8 . 1 0 K}$ & $\mathbf{6 0 . 0 K}$ & $\mathbf{5 5 0 . 0 K}$ \\
\hline 1.5 & 75.384 & 467.82 & $8.557 \mathrm{~K}$ & & \\
\hline 3.0 & 49.03 & 469.3 & $11.5 \mathrm{~K}$ & & \\
\hline 4.0 & 43.30 & 458.1 & $12.3 \mathrm{~K}$ & & \\
\hline 5.0 & 41.47 & 442.7 & $12.75 \mathrm{~K}$ & & \\
\hline 7.0 & 38.32 & 450.5 & $13.40 \mathrm{~K}$ & & \\
\hline 10.0 & 39.04 & 468.5 & $16.00 \mathrm{~K}$ & $160.0 \mathrm{~K}$ & \\
\hline 23.0 & 41.18 & 639.0 & $20.30 \mathrm{~K}$ & $64.5 \mathrm{~K}$ & $369 \mathrm{~K}$ \\
\hline
\end{tabular}


Table-IV: Electrical Properties of Functional Phases

\begin{tabular}{|c|c|c|}
\hline $\begin{array}{c}\text { Conducting } \\
\text { Phase }\end{array}$ & $\begin{array}{c}\text { Resistivity at } \\
298 \mathrm{~K} \text { in } \\
\text { Ohm.cm }\end{array}$ & $\begin{array}{c}\text { TCR } \\
\text { In ppm/ } / \\
{ }^{\circ} \mathrm{C}\end{array}$ \\
\hline $\mathrm{RuO}_{2}$ & $4 \times 10^{-5}$ & +5000 \\
\hline $\mathrm{Bi}_{2} \mathrm{Ru}_{2} \mathrm{O}_{7}$ & $2 \times 10^{-4}$ & 0 \\
\hline $\mathrm{Ru}$ Metal & $6 \times 10^{-6}$ & - \\
\hline
\end{tabular}

\section{IV.3.2. Degenerate Semiconduction (Uniform Model):}

According Sartain to et al [1], the conduction in the fired film resistor was due to degenerate semiconduction in conduction band of glass. Heavy doping of the binding glass by the metallic constituent during firing cycle was thought to be responsible for the proposed degeneracy. However, such a doping requires fair amount of dissolution of Ruthenium either by a prolonged chemical reaction or by prolonged diffusion into glass phase. This dissolution is possible provided the thick film resistor is fired through a prolonged firing cycle with large soak time at peak firing temperature.

\section{IV.3.3. Conducting chains:}

Polinski [2] has attributed the electrical conduction in fired thick film resistor to be through connected chains of conducting particles of uniform composition. Conducting particles were supposed to have become linked into these paths either by random contacts achieved during firing or by actual particle-particle sintering. Variation of resistance with volume-fraction of metal oxide was attributed to variation of path density and tortuosity. In later modification, the presence of grain boundaries either in the conducting particles itself or in their sintered interfaces were also considered as additional scattering centers.

Brady [3] tried to explain the TCR by invoking particle-to-particle contact area induced by thermal expansion. He attributed the TCR to thermal expansion differences among metal oxide particles (Forming conducting channel), the glass and the substrate and the film-resistance was expected to increase linearly with temperature.

\section{IV.3.4. Non-Tunneling Barrier Conduction:}

This model [4-6] assumes the formation of channels of metallic particles or sintered agglomerates occasionally interrupted by barriers of semiconducting or poorly insulating materials. These regions could be inclusions of the glass phase doped by nearby metallic constituent. Regardless of its origin, the barrier is supposed to be nontunneling type in the sense the electronic transport through the barrier was assumed to be by a non-tunneling mechanism such as space charge-limited conduction for carriers injected into a barrier band, extrinsic band conduction in the barrier with carriers supplied by ionizing acceptors or donors or Poole-Frenkel non-tunneling impurity type conduction in the barriers. These non-tunneling processes conceivable for the inter-particle regions are expected to be largely temperature dependent.

\section{IV.3.5. Electron hopping mechanism:}

This model assumes that the metal oxides form a deep band of states within the band gap of the glass and owing to randomness of glass host and spatial distribution of impurities, the charge carriers were expected to be localized. Electrical conduction, in this case, was thought to be by electron hopping showing large temperature dependence [18]. The stretched exponential behavior of conductivity with temperature at low temperatures was explained based on a tunneling-assisted hopping between conducting particles while strong piezoresistive nature of the fired resistors was attributed to inter-particle conduction mechanism [19].

\section{IV.3.6. Band Conduction:}

Assuming another possibility of inter- particle material behaving as simple potential barrier between metal oxide particles [20], conduction was proposed to be through the barrier by ordinary band conduction or by space charge limited conduction. The temperature dependence of resistance in these cases thought to arise from the energy 
required to excite an electron from the Fermi level and inject it into the barrier band. Thus basing on low activation energies observed it was presumed that the barrier band is located very close to the Fermi level of the metal oxide.

\section{IV.3.7. Schottky Barrier Conduction:}

Carcia et al [6] proposed that the presence of semiconducting regions between the metal oxide particles (or groups of particles) would lead to the formation of Schottky barriers at metal-semiconductor interface. It was suggested that these add up significantly to the channel resistance and the resistive contribution of semiconducting regions could be described better by the following expression:

$$
\mathrm{Rs}=\mathrm{R} 0 \exp (\mathrm{E} / \mathrm{kT}) \text {----------- (1) }
$$

Assuming Richardson-Schottky conduction mechanism to be the predominant one, the activation energy, E, could be the Schottky barrier height. Typical Schottky barrier heights are of the order of $0.5-1.0 \mathrm{eV}$.

\section{IV.3.8. Tunneling Barrier Conduction:}

Pike and Seager [7-8], basing on their experimental studies, proposed a tunneling barrier conduction model in which they assumed that the electrical conduction in thick film resistors is through a network of inter-connected chains of metal oxide particles. The metal oxide particles were thought to be separated from their neighbors on the chain by a thin glassy layer presumed to be formed during firing process as a natural feature of liquid phase-sintering.

Conduction through these layers (barriers) was presumed to be by a tunneling mechanism and the tunnel barriers were supposed to contribute mainly to the resistance of a given chain. They derived an expression of following type to explain the observed conduction behavior in fired resistor:

$$
\mathrm{R}(\mathrm{T})=\mathrm{R}_{\mathrm{BO}} \exp (\mathrm{EA} / \mathrm{kT})+\mathrm{R}_{\mathrm{MO}}(1+\mathrm{bT}) \text {------ (2) }
$$

Where the first term on right hand side of the equation is due to tunneling barrier and the second term is due to metal oxide and EA $\{=(1 / 2)$ EC $\}$ is the half of the electrostatic charging energy that an electron, from an initially neutral conducting particle, must overcome before tunneling to an adjacent particle through the barrier. Though the classical tunneling models [8] dealing with perfect dielectric, free of impurities, predict thin $(=20 \AA)$ high potential barriers for thick film resistors, the geometrical separation between conducting particles in actual fired resistors was found to be on the average of about 50 to $100 \AA$. However, the impurities in glass were thought to provide resonant centers for barrier tunneling conduction.

\section{IV.3.9. Narrow Band Conduction:}

Hill [9] tried to explain the conduction processes in thick film resistor based on a narrow band model. He proposed that diffusion of transition metal ions into glass matrix during firing give rise to a narrow band of states in the inter granular material. According to him, these diffused atoms bond with oxygen atoms of silica network and so form $\Pi+$ bonds of same type which give a narrow conduction band in transition metal oxides as proposed by Goodenough [10]. At sufficiently high concentration $\Pi+$ bonds overlap to form a narrow band of states which could be half-filled. At low temperatures the charge carriers (Electrons) get trapped and material will be insulating. At high temperatures they make the matrix weakly metallic. Hill assumes that electrically no sharp boundary exists between conducting particles and glass. Instead a broad transition region, highly doped, in both directions exists. The effect of this transition region will be to increase the resistance of the material in the particles and decrease the resistance of the interparticulate spacing.

\section{IV.3.10. Conduction by Percolation:}

An alternative model proposed by Ansell [11] and Hill [12] and later applied by Prudenziati [13-15] to TFRs assumes that the impurities dope the glass interface between conducting particles and conduction in the interface takes place by variable hopping between impurity sites. According to Cattaneo et al the fired resistor is made up of conductive grains embedded in a glassy matrix and the conductive grains were pictured as multi-valued resistor network through which the carriers are thought to move by percolation. The network was supposed to be consisting of:

(a) Conductive grains with purely ohmic contact between them

(b) Grains or groups of grains with a non-zero contact resistance and

(c) Grains or groups of grains with very high contact resistance. 
Further they assume that the resistance of percolation path dominates the resistance of network and tunneling mechanism proposed by Pike et al accounts for low contact resistances between adjacent grains. They derived following expressions for resistivity and T.C.R. :

$\rho=\rho_{\mathrm{o}} \mathrm{T} \exp (\mathrm{To} / \mathrm{T}) 1 / 4 ; \mathrm{To}=16 \alpha^{3} / \mathrm{kN}_{\mathrm{o}}---(3)$

$\left.\mathrm{TCR}=(1 / \rho)(\mathrm{d} \rho / \mathrm{dT})=(1 / 2 \mathrm{~T})[1-1 / 2)\left(\mathrm{T}_{\mathrm{o}} / \mathrm{T}\right) 1 / 4\right]--(4)$

Where ' $\mathrm{N}_{\mathrm{o}}$ ' is density of conductive grains per unit volume and per unit energy and ' $\alpha$ ' is a parameter correlated to the grain size and glass characteristics.

This model was based on the optical inspection, X-ray diffraction, SEM, Microprobe and TEM studies carried out on fired resistors.

Abdurkhmanov [21] from his studies on conduction mechanism in thick film resistors formed by silicate glass doped with ruthenium oxides proposed formation of diffusion zones around the dopant particles in the softened glass during firing of printed resistors due to which doping glass would become conductive. He attributed the conduction in the fired films to these highly conductive zones which act as percolation levels for for free charge carrier movement.

Explaining reduction in conductivity of films fired at temperatures above $800 \mathrm{~K}$, Abdurkhmanov [22, 23] proposed formation of nanocrystals during firing which become effective centers of localization of free charge carriers. These centers enable a variable range hopping and he reported formation of a narrow impurity subband of about $0.03 \mathrm{eV}$ just above or abutted on valance band of glass in samples fired at low temperature. According to him when the samples are fired at high temperatures, the subband moves up, getting well separated from the valance band of glass leading to a reduction in conductivity.

\section{IV.3.11. Barrier Conduction:}

Pfeiffer et al [16] deduced from their studies that the TCR of a TFR is independent of length and number of conducting paths in a resistor and, where the basic structure is unchanged, solely dependent on the barrier between the conducting phase and the glass phase. They derived an expression for resistance and TCR which was later slightly modified by Pitt [17] and is given below :

$$
\begin{aligned}
& \mathrm{R}(\mathrm{T})=(\mathrm{i} / \mathrm{j})\left\{\mathrm{f}_{\mathrm{c}} \rho_{\mathrm{c}}\left[1+\alpha\left(\mathrm{T}-\mathrm{T}_{\mathrm{o}}\right)\right]+\left(1-\mathrm{f}_{\mathrm{c}}\right) \rho_{\mathrm{g}}(1+\mathrm{E} / \mathrm{kT})\right\}--(5) \\
& \mathrm{TCR}=\left\{\mathrm{f}_{\mathrm{c}} \rho_{\mathrm{c}} \alpha-\left(1-\mathrm{f}_{\mathrm{c}}\right) \rho_{\mathrm{g}}\left(1+\mathrm{E} / \mathrm{kT} \mathrm{T}^{2}\right)\right\} /\left\{\mathrm{f}_{\mathrm{c}} \rho_{\mathrm{c}}\left[1+\alpha\left(\mathrm{T}-\mathrm{T}_{\mathrm{o}}\right)\right]+(1-\mathrm{fc}) \rho_{\mathrm{g}}(1+\mathrm{E} / \mathrm{kT})\right\} \ldots \text { (6) }
\end{aligned}
$$

Where $(i / j)$ represents the ratio of number of conducting particles in a chain with respect to the number of chains, connected parallel in the resistor, $f_{c}$ is the volume fraction of the conducting phase, ' $E$ ' the activation energy of conduction, ' $\alpha$ ' the TCR of conducting phase $\rho_{c}$ and $\rho_{g}$ are resistivities of conducting phase and glass phase (Doped) respectively.

\section{Discussions:-}

A close examination of the resistance vs temperature plots (Fig1 to Fig.16) indicate that the plots can be divided into following three groups basing on certain general trends of similar nature :

(a) Plots in which the room temperature resistance of fired film is relatively high and decreases exponentially with temperature from 20 to $300^{\circ} \mathrm{C}$. They include Fig.8 (a), 9 (a) and 10.

(b) Plots in which the room temperature resistance of fired film is relatively low and increases linearly with temperature from $20^{\circ} \mathrm{C}$ to $300^{\circ} \mathrm{C}$ similar to that of a metal. They include Fig.6, 7, 8(b) and 9(b).

(c) Plots in which the as fired value of resistance is low and TCR varies non-linearly with temperature from 20 to $300^{\circ}$ C. These include Fig. 11, 12, 13, 14 and 15 .

\section{Group (a) curves:}

The large room temperature resistance of $1 \mathrm{k}$ and $10 \mathrm{k}$ films fired at temperatures below $650^{\circ} \mathrm{C}$ and $675^{\circ} \mathrm{C}$ respectively clearly indicate the existence of insulating barrier with high energy gaps. Since the temperatures fall 
above burnout region of $500^{\circ} \mathrm{C}$, the insulating barriers are either glass particles or micro-cracks, which isolate the conducting regions. Conduction mechanism in these films could be any of the non-tunneling barrier type discussed at 4.3 above. The plots obtained for 100k-paste resistor fired at $700^{\circ} \mathrm{C}$, for 1.5 minute soak time (Fig.10) and for 1 Meg paste resistors fired at $850^{\circ} \mathrm{C}$, for 15 minutes (Fig.14) exhibit similar behavior. Though the volume fraction of conducting phase in $100 \mathrm{k}$ paste resistor is relatively larger than that of $1 \mathrm{Meg}$ paste resistor, since firing temperature and soak time are relatively small, substantial increases in size of glass particle or distance between conducting grains is ruled out. It may be presumed that small glass particles, which are not well sintered, form the barriers between the conducting particles. The non-linear temperature behavior of these resistors as shown in Fig 10 and 14 supports this view.

Group (b) curves: (1, 100, 1k and 10k Paste Films fired with 1.5 minute soak time):

All the curves in this group (Fig 6, 7, 8b and 9b) exhibit almost a linear increase in normalized resistance with temperature between $20^{\circ} \mathrm{C}$ and $300^{\circ} \mathrm{C}$ indicating predominantly metallic nature of these resistors.

Since these films are not kept for long soak times (Only 1.5 minutes), substantial sintering of the functional phase particles is not possible. Since the organic binder is totally burnt out the functional phase particles are likely to be in contact with one another. The relatively small increase in resistance of these resistors may be attributed to simple thermal expansion of the substrate which is likely to reduce the contact area of conducting particles.

None of the equations discussed above from 1 to 6 could explain the observed linear dependence of resistance as well as the independence of this linearity with firing temperature. Hence it may be presumed that the doping of glass or formation of semiconducting or insulating barriers between conducting particles/grains has not yet set in the thick film structure in a significant way to give rise to either predominant barrier tunneling conduction or percolation conduction which are largely temperature dependent and predict a non-linear behavior. This is understandable since neither the soak time of ninety seconds nor the peak firing temperature are adequate enough to yield a microstructure predominant with doped glass nor an insulating barrier. The observed behavior in these resistors is more in agreement with mechanism proposed at IV.3.3 where conducting chains were presumed to be responsible for the film conduction

One interesting behavior observed in case of $100,1 \mathrm{k}$ and 10k paste resistors is low TCRs associated with high room temperature resistance and high TCR when the room temperature resistance is low as shown in Table-II. These are the resistors, which exhibited metallic type behavior in their temperature dependence of resistance.

Fast firing profiles are expected to induce stresses in the fired films due to which the as fired values of resistance may drift irreversibly at room temperature over a period of time or when subjected to repeated thermal cycling. This drift was often attributed to stress relaxation. To explore this, the fast fired resistors were subjected to repeated thermal cycling and no such drift was observed except in case of $1 \mathrm{ohm}$ and $100 \mathrm{ohm}$ paste resistors fired at $500^{\circ} \mathrm{C}$. These resistors also after a few thermal cycles approach a constant value of resistance as shown in Fig.4 and 5 respectively

\section{Group c) curves:}

All the curves (Fig 11, 12, 13, 14 and 15) in this group exhibit a non-linear dependence of resistance on temperature from 20 to $300^{\circ} \mathrm{C}$. Since these films are well sintered at higher temperature for longer times it may be presumed that glass particles have melted, flowed and grew in size and smaller conducting particles adhere to larger glass particles. Conduction mechanisms in these films may be well in agreement with those models, which predict a non-linear temperature dependence of resistance. With increasing degree of sintering in low resistance paste resistors $(100,1 \mathrm{k})$ conduction can arise due to percolation conduction, narrow band conduction and non-tunneling barrier conduction. In case of high resistance paste resistors $(100 \mathrm{k}, 1 \mathrm{M})$ which are subjected to prolonged sintering leading to doping of glass phase with conducting particles the conduction is likely to arise from electron hopping mechanism and nontunneling barrier conduction mechanisms involving high activation energies.

The firing cycle time (or soak time in turn) did not have much influence on TCR of $1 \mathrm{k}$ and 10k paste resistors. 100ohm paste resistors on the other hand exhibited a significant decrease in TCR at 24.25 cycle time after which it has remained constant. TCE of all these resistors, however, started decreasing after one hour firing cycle time. 
The anomaly observed in case of $100 \mathrm{~K}$ paste resistors which showed low resistance when fired at $700^{\circ} \mathrm{C}$ but drifted to high resistance (Table II) when fired at higher temperatures for 1.5 minutes soak time may be aettributed to initial contact of functional phase particles at low firing temperatures. This contact is likely to be inturrupted at higher firing temperatures due to incresing size of glass particles leading to the observed high resistance. Interestingly this is well in agreement with the model proposed by Abdurkhmanov [22, 23] as explained above. As per this model, the observed low resistance in samples fired at $700^{\circ} \mathrm{C}$ may be attributed to the proximity or abutting of the narrow impurity subband formed by nanocrystalline centers to the valance band of glass. At higher firing temperatures the subband is likely to be well separated from the valance band leading to observed high resistance.

\section{Conclusions:-}

Printed thick film resistors were subjected to different temperatures of firing and soak times and their structures were frozen. Electrical properties of these films were studied and correlated with various electrical conduction mechanisms possible in these structures.

\section{Acknowledgements:-}

The author is thankful to Sri G.H.Sharma, GM, Microelectronics Division, ITI Ltd, Bangalore for his encouragement in carrying out this work. The author is also thankful to ITI Ltd., Bangalore, India for providing the facilities to carry out this work.

\section{References:-}

1. C.C.Sartain, W.D,Ryden and A.W.Lawson, J.Non-Cryst.Solids 5 (1970), p55.

2. P.W.Plonski, Proc. Of 1967 Electronic Component Conf. Washington D.C., (1973), p 153.

3. L.J.Brady, Proc. Of 1967 Electronic Component Conf. Washington D.C., (1967), p 238.

4. Y.Taketa and M.Haradome, IEEE Trans Parts Hybrids Packaging, PHP-10 (1974), p74.

5. B.Walton, Radio Electronic Eng., 45 (1975), p139.

6. P.F.Carcia, S.E.Champ and R.B.Flipen, Proc. Of 1976 Electronic Component Conf. Washington D.C., 1976, p 156

7. R.W.Vest "Material Science of Thick Film Technology", Am.Ceram.Soc.Bull., Vol.65, No.4 (1986), pp 631636.

8. G.E.Pike and C.H.Seager, 'Electrical Properties and Conduction Mechanisms of Ru-based TFRs', J.Appl.Phys.,48 (1977), 12, p 5152-5169

9. R.M.Hill 'Electrical Transport in thick Film Resistors', Invited Paper, Europian Hybrid Microelectronics Conference, Ghent, (1979), p 95-104

10. J.B.Goodenough, 'Covalency criterion for localized versus collective electrons in oxides with perovskite structures' J Appl.Phys., 37 (1966), 1415

11. M.P.Ansell, Electro Compo.Sci.Technol., 3 (1976), 141.

12. R.M.Hill and T.J.Coutts -, 'Charge Tranfer in Discontinuous Thin and Cermet Films', Thin Solid Films, 42(1977), p 201-212

13. M.Prudenziati, 'Conduction Mechanisms in thick Film resistors' Third Europian Hybrid Microelectronics Conference, Avignon (1981), p 1-10

14. C.Jacoboni, M.Prudenziati and A.Rizzi, 'A Simulative Approach of Electron Conduction in Thick Film Resistors' ibid, p 11-18

15. C.Canali, D.Malavasi, B.Morten, M.Prudenziati and A.Taroni, J.Appl.Phys. 51 (1980), p3282.

16. R.J.Pfeiffer and RJ.Bouchard, Ceramic Trans.33 (1993)

17. Keith Pitt, J.Material Science: Materials in Electronics 7 (1996), p187.

18. V.Ambegaokar, B.I.Halperin and J.S.Langer, Phys Rev (4) (1971), p 2612-20 .

19. C.Grimald, 'Conduction Mechanism in printed thick-film resistors' p 112, Book 'Printed Films - Materials science and applications in sensors, electronics and photonics' Woodhead Publishing series in Electronics and Optical Materials, (2012).

20. N.F.Mott \& E.A.Davis, Electronic processes in Non-crystalline materials, Clarendon Press, Oxford (1971).

21. Gulmurza Abdurakhmanov, 'On the Conduction Mechanism of Silicate Glass Doped by Oxide Compounds of Ruthenium (Thick Film Resistors)', World Journal of Condensed Matter Physics, 1 (2011), 19-23.

22. Gulmurza Abdurakhmanov, 'On the Conduction Mechanism of Silicate Glass Doped by Oxide Compounds of Ruthenium (Thick Film Resistors). 2. Nanocrystals in the Glass and Charge Carrier's Localization', Journal of Materials Science, January 2011, 1(1), 12-17. 
23. Gulmurza Abdurakhmanov, 'On the Conduction Mechanism of Silicate Glass Doped by Oxide Compounds of Ruthenium (Thick Film Resistors). 3. The Minimum of Temperature Dependence of Resistivity', World Journal of Condensed Matter Physics, (2014), 4, 166-178. 